\title{
Calidad de poroto (Phaseolus vulgaris L.) almacenado en silobolsa en condiciones de intemperie en relación a la presencia de materias extrañas y granos partidos
}

\author{
Godoy, Adriana Iris \\ Estación Experimental Agropecuaria Salta (EEA Salta), Instituto Nacional de Tecnología Agropecuaria \\ (INTA); godoy.adriana@inta.gob.ar
}

Godoy, Adriana Iris (2019) Calidad de poroto (Phaseolus vulgaris L.) almacenado en silobolsa en condiciones de intemperie en relación a la presencia de materias extrañas y granos partidos. Rev. Fac. Agron. Vol 118 (2): 1-8. https://doi.org/10.24215/16699513e016

\begin{abstract}
El objetivo del trabajo fue estudiar el deterioro del poroto blanco alubia almacenado en silobolsa con la presencia de materias extrañas y granos partidos. Se evaluaron silobolsas con diferentes contenidos iniciales de humedad, materias extrañas, granos partidos y granos manchados. Se midió la evolución de estos parámetros y la concentración de dióxido de carbono. Se registró humedad relativa y temperatura del aire intergranario. Se utilizó la actividad acuosa como parámetro de actividad microbiana. Los resultados indican que el manchado de los granos aumentó con altos contenidos iniciales de manchado, humedad y materias extrañas, que coincidió con el incremento de microorganismos. Estos últimos se localizaron según la ubicación del material fino en la base de la bolsa, o en puntos húmedos del estrato superior producto de la condensación. Bajos valores de humedad y materias extrañas evidenciaron control microbiano por humedad relativa $<70 \%$. Se observó interacción entre los efectos de materias extrañas y granos partidos, que generó el manchado de los granos, favorecida por períodos prolongados y altas temperaturas. El efecto de los granos partidos se relacionó con el contenido de humedad y el efecto del material extraño con el tiempo. Se observó la estratificación de la humedad. La concentración de dióxido de carbono aumentó con el incremento de la temperatura. Los incrementos de la actividad acuosa se relacionaron con altas proporciones de materias extrañas y granos partidos presentes en el granel, y con elevados contenidos de humedad de los mismos y del grano, lo cual ocasiona mayor actividad microbiológica.
\end{abstract}

Palabras clave: bolsas plásticas, atmósfera modificada, deterioro de granos, material fino

Godoy, Adriana Iris (2019) Quality of stored bean (Phaseolus vulgaris L.) in outdoor silo bag related to the presence of foreign matters and broken grains. Rev. Fac. Agron. Vol 118 (2): 1-8. https://doi.org/10.24215/16699513e016

The aim of this work was to study the spoilage process in bean's quality stored in silo bags with foreign matters and broken grains. Conventional silo bags were evaluated. They had different initial contents of: grain moisture, foreign matters, broken grains and spotted grains. This parameters evolution was evaluated and the carbon dioxide concentration too. The inter grain relative humidity and temperature air were registered. The water activity was used as a microbiological activity parameter. Results shows an important increase of the spotted grains percentage with high initial contents of spotted grains, humidity and foreign matters. That increase coincided with the microorganisms' increase. The microorganisms were located according to the location of the thin material in the base of the bag, or in upper layer damp points, product of condensation. Low values of moisture and foreign matters had showed microorganisms control because the intergranular air relative humidity reached percentages lower than $70 \%$. An interaction between effects of foreign matters and broken grains was observed. This interaction generated spotted grains and was favored by long storage periods and high temperatures. The effect of the broken grains showed a strong relationship with the grain moisture content. The effect of foreign matters gained importance through the storage time. The moisture stratification was observed. The carbon dioxide concentration increased with temperature's increase. The water activity increase was related with the high percentages of foreign matters and broken grains, and it high moisture contents. The grain moisture has a positive effect on microorganisms as well. Those factors determinate of the microbiological activity increase.

Keywords: plastic bags, modified atmosphere, spoilaged grains, fine material

https://revistas.unlp.edu.ar/revagro

Recibido: 05/12/2017

Aceptado: $28 / 07 / 2019$

Disponible on line: $27 / 12 / 2019$

ISSN 0041-8676 - ISSN (on line) 1669-9513, Facultad de Ciencias Agrarias y Forestales, UNLP, Argentina 


\section{INTRODUCCIÓN}

La producción de poroto (Phaseolus vulgaris L.) en Argentina se concentra en las provincias de Salta y Jujuy, donde se cultivaron 412.115 hectáreas en la campaña 2016-2017 (Paoli et al., 2017). El tipo comercial de mayor rentabilidad es el poroto blanco alubia (Tubello \& Picollo, 2002) que se comercializa a través de acuerdos entre partes, con altas exigencias de calidad (el $90 \%$ de la producción se exporta a España, Italia, Turquía, Argelia, como destinos principales). La incorporación del silobolsa al manejo de poroto acompañó el incremento de la producción de 305.019 toneladas (t) en 2010 a 618.173 t en 2017 (Paoli et al., 2017).

En el interior del silobolsa se modifica la atmósfera por la respiración del granel, lo cual reduce la concentración de oxígeno $\left(\mathrm{O}_{2}\right)$ y aumenta la de dióxido de carbono $\left(\mathrm{CO}_{2}\right)$ (Cardoso et al., 2009), aspectos que limitan la actividad bilógica y conservan el grano (Bartosik et al., 2009).

Como resultado de la cosecha directa ineficiente (es decir realizada con cosechadoras que carecen del equipamiento y la regulación apropiadas para el tratamiento de los granos de poroto), el manejo inadecuado de malezas y el uso de variedades de maduración despareja (De Simone \& Godoy, 2006; Godoy et al., 2006) desde hace unos años se observan silobolsas de poroto con alto grado de materias extrañas (ME) y granos partidos (Godoy \& De Simone, 2010). Esta situación generaría en el aire intergranario una humedad relativa de equilibrio (HRE) propicia para el desarrollo de microorganismos (Giner, 1994; Abadía \& Bartosik, 2013). Sumado a esto, Weller \& Saettler (1980) observaron durante la cosecha la infección externa del grano con bacterias presentes en el polvo de tejidos infestado.

Existen diversos estudios referidos al almacenaje en silobolsa. Bartosik et al. (2009) evaluaron el efecto del contenido de humedad del grano $(\mathrm{CH})$, la temperatura $\left(\mathrm{T}^{\circ}\right)$ y el tiempo sobre la calidad de maíz, trigo, soja y girasol almacenados en silobolsa. Estos autores midieron la concentración de gases, observando que los cambios se acentúan al final del almacenamiento, en especial en granos húmedos. Concluyen que los parámetros evaluados tienen efecto en la calidad, y que la concentración de $\mathrm{CO}_{2}$ puede utilizarse como indicador de la actividad biológica. Cardoso et al. (2009) estudiaron la evolución del $\mathrm{CH}$ de granos individuales de maíz y soja en silobolsa. Ellos observaron que el $\mathrm{CH}$ individual se vuelve homogéneo y que el $\mathrm{CH}$ promedio de los granos del estrato superior de la bolsa aumenta debido a movimientos de humedad por convección de vapor y posterior condensación. También observaron la estratificación del material fino en la base de la bolsa. De Simone et al. (2009) estudiaron el comportamiento del poroto en bolsas plásticas experimentales $(150 \mathrm{~kg})$ en relación a su $\mathrm{CH}$ inicial, el deterioro de los granos (por hongos y bacterias) y el tiempo. Los autores mencionan que cuanto mayor es el $\mathrm{CH}$ del grano menor es su calidad, que los granos con elevado deterioro inicial pierden calidad independientemente del $\mathrm{CH}$ y que el PG disminuye a los 150 días. Ellos concluyen que es factible almacenar en condiciones seguras granos sanos, limpios y secos $(\mathrm{CH} 12 \%)$ hasta 150 días. De Simone \& Godoy (2009) estudiaron los mismos parámetros que De Simone et al. (2009), en silobolsas comerciales de poroto $(200 \mathrm{t})$ y observaron su disminución en el mismo periodo de tiempo. A su vez, Godoy (2014b) estudió la concentración de $\mathrm{CO}_{2}$ en silobolsas comerciales de poroto y estableció valores de referencia de acuerdo a la condición del grano y del plástico. Este autor observó que existe una relación entre el $\mathrm{CH}$ del grano, la composición del granel y la concentración de $\mathrm{CO}_{2}$.

La Humedad Relativa de Equilibrio (HRE) es la relación de equilibrio entre la humedad relativa del aire (HR) y el $\mathrm{CH}$ del grano. La misma define la curva de HRE que depende de la $\mathrm{T}^{\circ}$ y del tipo de grano. Abadía \& Bartosik (2013) y Giner (1994) destacan la importancia de considerar la HRE o su equivalente en granos (actividad acuosa (aw)) como parámetro de estabilidad microbiana. La misma no debe superar $70 \%$ de HR o 0,7 de aw (mínimo requerido por los hongos para crecer). En 1998, De Simone construyó la curva de HRE a $25^{\circ} \mathrm{C}$ para poroto blanco. En tal sentido Godoy (2014a) estudió el comportamiento de la atmósfera intergranaria en silobolsas experimentales de poroto $(400 \mathrm{~g})$ en función de contenidos y humedades conocidos de ME y granos partidos. Concluyó que existe una relación entre $\mathrm{HR}$ y $\mathrm{CH}$, donde $\mathrm{CH}$ del grano aumenta y genera una condición de aw favorable para el desarrollo microbiano con la presencia de $\mathrm{ME}$ húmedo.

El $90 \%$ de los productores de poroto blanco alubia que almacenan la producción en silobolsa, lo hacen con altos contenidos de ME y granos partidos. Se desconocen las pérdidas de calidad comercial causadas por la actividad microbiológica, como así también el efecto de estos parámetros. Por tal motivo, el objetivo de este trabajo fue evaluar el deterioro de la calidad comercial de poroto almacenado en silobolsa en condiciones de intemperie, con presencia de ME y granos partidos. Para ello se analizaron los cambios en la humedad por estratos y se determinaron qué factores ocasionan dichos cambios. También se estudió la ubicación de los microorganismos en el granel. Asimismo, se analizó el comportamiento de la concentración de dióxido de carbono en relación a la condición del grano y su entorno, y se identificaron los factores evaluados que podrían utilizarse como parámetros del tiempo de almacenamiento seguro.

\section{METODOLOGÍA}

El estudio se realizó en el establecimiento ALIMAR S.A. (General Güemes, Salta, Argentina). Se escogieron 5 silobolsas de poroto blanco alubia con diferentes valores iniciales de: $\mathrm{CH}$ del grano (\%); $\mathrm{ME}(\%)$; granos partidos (\%), y granos manchados (\%). Se designaron como bolsa A, B, C, D, E (Tabla 1).

\section{Obtención de muestras.}

Se empleó un muestreo dirigido al cierre de la bolsa, el punto crítico y el óptimo. Estos últimos puntos corresponden al máximo y mínimo valor medido de $\mathrm{CO}_{2}$, respectivamente, determinados con el método de Bartosik et al. (2009). 
Tabla 1. Características compositivas del granel de cada bolsa. Condición inicial, final y tiempo de almacenamiento. Valores promedio de cada silobolsa.

\begin{tabular}{lccccccccccc}
\hline Bolsa & \multicolumn{1}{c}{ A } & \multicolumn{1}{c}{ B } & \multicolumn{1}{c}{ C } & \multicolumn{2}{c}{ D } & \multicolumn{2}{c}{ E } \\
\hline Condición & Inicial & Final & Inicial & Final & Inicial & Final & Inicial & Final & Inicial & Final \\
Contenido Humedad (\%) & 9,7 & 9,3 & 10,5 & 10,2 & 9 & 10,4 & 12,2 & 12,5 & 9,9 & 9,5 \\
Materias Extrañas (\%) & 1,7 & 1,7 & 1,9 & 1,9 & 2 & 2 & 2,3 & 2,3 & 2,7 & 2,7 \\
Granos partidos (\%) & 4,6 & 4,6 & 2,6 & 2,6 & 2,8 & 2,8 & 4,2 & 4,2 & 3,8 & 3,8 \\
Granos manchados (\%) & 2 & 7,63 & 6,2 & 6,86 & 4,7 & 10,1 & 3,1 & 5,3 & 3,8 & 7,8 \\
Tiempo de almacenaje (días) & \multicolumn{2}{c}{124} & \multicolumn{2}{c}{74} & \multicolumn{2}{c}{62} & \multicolumn{2}{c}{105} & & 120 \\
\hline
\end{tabular}

Se consideraron los valores de referencia de $\mathrm{CO}_{2}$ para poroto (Godoy, 2014b). Se extrajeron muestras del nivel superior (1,2 $\mathrm{m}$ de altura) e inferior $(0,1 \mathrm{~m}$ sobre el nivel del suelo). Por cada fecha de muestreo se evaluaron los puntos: 1) cierre arriba, 2) cierre abajo, 3) punto óptimo arriba, 4) punto óptimo abajo, 5) punto crítico arriba, 6) punto crítico abajo. Los muestreos se realizaron cada siete a 15 días en función de las condiciones climáticas en todas las bolsas, desde el 28/07/2011 hasta 05/01/2012, utilizando un calador convencional (De Simone \& Godoy, 2009). Cada muestra pesó $450 \mathrm{~g}$ (SAGPyA, 1994). Se ingresó horizontalmente al silobolsa haciendo un corte del plástico con la punta del calador. El plástico se reparó según lo propuesto por Cardoso et al. (2009).

Determinación de los parámetros evaluados.

Se separaron las ME (tierra, cascotes, hojas, vainas, etc.) de los granos partidos utilizando una zaranda de 4,5 $\mathrm{mm}$ de paso (SAGPyA, 1994). El peso de ME se expresó como porcentaje del peso total de cada muestra. Los granos partidos separados y pesados también se expresaron como porcentaje. Los granos sanos se revisaron visualmente para detectar el manchado de la testa y su peso se expresó como porcentaje. Los granos manchados se analizaron en el laboratorio de Sanidad Vegetal del INTA Salta para la determinación de hongos y bacterias. El número de granos afectados se expresó como porcentaje del total de manchados. Se empleó como complemento el test de patogenicidad en bacterias.

\section{Humedad y temperatura del grano y de la atmósfera intergranaria.}

El $\mathrm{CH}$ del grano fue determinado en poroto sano y limpio según norma ASAE S352 (1996a). También se utilizó un humedímetro (marca Motomco) para determinar $\mathrm{CH}$ y temperatura $\left(\mathrm{T}^{\circ}\right)$ de los granos. La HR y la $\mathrm{T}^{\circ}$ intergranaria de la bolsa $A$ fueron medidas utilizando seis sensores I-button datalogger (DS 1923 Termochrom, USA) que se programaron para una lectura horaria durante todo el almacenamiento. Se colocaron al inicio del embolsado en el estrato superior (tres sensores) y en la base (tres sensores) equidistantes a lo largo de la bolsa (Figura 1).

Con los datos de HR y $\mathrm{CH}$ se determinó la HRE empleando la curva de HRE propuesta por De Simone (1998). Se consideró HRE $>70 \%$ como condición insegura de almacenamiento (Abadía \& Bartosik, 2013; Giner, 1994).

\section{Análisis estadístico.}

Se utilizó el programa STATISTICA 7.0. Cada fecha de muestreo se consideró una repetición. Se empleó ANOVA de efectos principales (confianza: 95\%; $p<0,05$ ) para evaluar el comportamiento del $\mathrm{CH}$ y de los microorganismos. Los predictores categóricos fueron las condiciones (1: inicial, 2: final) y los puntos de muestreo y las variables dependientes: $\mathrm{CH}(\%)$, hongos (\%) y bacterias (\%). En la bolsa A se efectuó ANOVA con un solo predictor (confianza: 95\%; $p<0,05$ ) para analizar los registros de los sensores. El predictor fue cada sensor y las variables dependientes: HR (\%) y $\mathrm{T}^{\circ}$ $\left({ }^{\circ} \mathrm{C}\right)$. También se realizó una matriz de correlación entre todos los parámetros, y se escogieron las significativas. La interacción entre los parámetros se evaluó con ANOVA factorial. Se agruparon las bolsas de acuerdo con su contenido de ME y granos partidos: ME1/Partidos I: Bolsa B; ME1/Partidos II: Bolsa A; ME2/Partidos I: Bolsa C; ME2/Partidos II: Bolsas D y E, donde: ME1<2\%; ME2>2\%; partidos $1<4 \%$; partidos $2>4 \%$.

\section{RESULTADOS}

Actividad microbiológica y atmósfera intergranaria. En la bolsa $A$ la proporción de hongos se redujo de $16 \%$ a $12,4 \%$ entre condición inicial y final sin observarse diferencias estadísticas significativas (d.e.s.) $(p=0,29)$. Los puntos de muestreo tampoco evidenciaron d.e.s. $(p=0,32)$. Los hongos se distribuyeron en el granel en la base de la bolsa, de acuerdo con la ubicación del material fino (Figura 2). El contenido de granos partidos fue mayor en el estrato inferior $(5 \%)$ que en el superior $(2,8 \%)$.

Las bacterias aumentaron levemente y se ubicaron también en la zona inferior de la bolsa (promedio de afección $3,5 \%$ ), aunque no se observaron d.e.s. entre puntos ni condiciones $(p>0,05)$ (menos de 50 Unidades Formadoras de Colonias (UFC)). La patogenicidad de las bacterias fue positiva desde el inicio.

La HR del aire intergranario se mantuvo por debajo de $60 \%$ durante el almacenamiento (Figura 1). Se observaron d.e.s. entre los registros de $\operatorname{HR}(p<0,05)$, con valores más altos en la parte superior de la bolsa, lo que evidencia su estratificación (Figura 1). La diferencia de HR entre condición inicial y final fue mayor en los sensores superiores (2\%). La $\mathrm{T}^{\circ}$ del aire intergranario siguió el patrón de la $\mathrm{T}^{\circ}$ ambiente con leves aumentos en el estrato superior, aunque sin d.e.s. $(p>0,05)$ (Figura 1). 


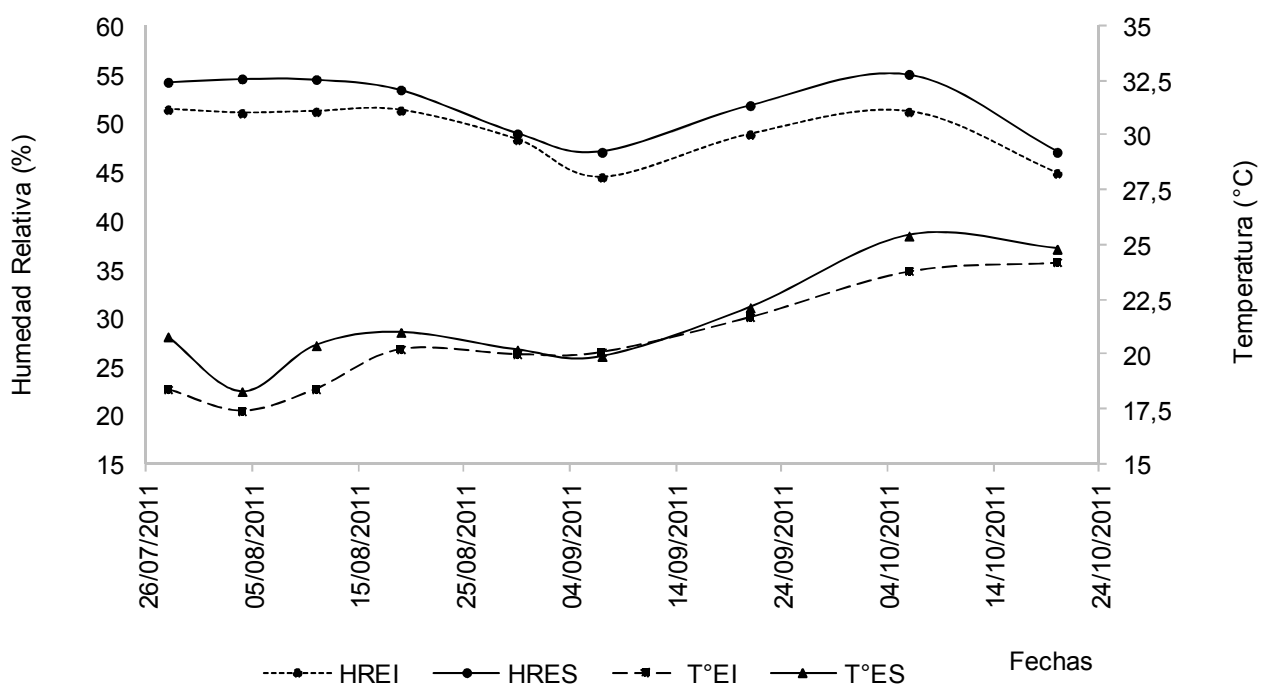

Figura 1. Evolución de la $H R(\%)$ y la $T^{\circ}\left({ }^{\circ} \mathrm{C}\right)$ del aire intergranario en el período de almacenamiento de la bolsa $A$ en el estrato inferior (EI) y el estrato superior (ES) de la misma.

Las bolsas $\mathrm{B}, \mathrm{C}$ y $\mathrm{E}$ tuvieron comportamientos semejantes a la bolsa $A$. Se produjo el control de microorganismos por la baja HRE, que se estima fue menor a $70 \%$, de acuerdo a los $\mathrm{CH}$ del grano (menos de $10,5 \%$ con un promedio sostenido sin d.e.s., $p<0,05$ ) y considerando la curva de CHE (contenido de humedad de equilibrio de los granos).

Los hongos disminuyeron en las bolsas $\mathrm{C}$ y $\mathrm{E}$ a $24 \%$ y $10 \%$ de afección final promedio, respectivamente, con una caída en el orden de $20 \%$. En la bolsa C se observaron d.e.s. entre condiciones y puntos de muestreo $(p<0,05)$, no así para la bolsa $E$, aunque se observaron tendencias decrecientes muy marcadas. En la bolsa $\mathrm{B}$ la afección por hongos se redujo $0,5 \%$, con un valor promedio final de $27 \%$, sin d.e.s. entre condiciones ni puntos de muestreo. El mayor control de bacterias se produjo en la bolsa $C$ (promedio de afección final $0,5 \%$ y d.e.s. entre condiciones y puntos de muestreo, $p<0,05)$.

En las bolsas con altos contenidos de ME y granos partidos ( $D$ y $E$ ) los microorganismos se ubicaron en la base de las bolsas (Figura 2) coincidiendo con la estratificación del material fino, al igual que en la bolsa A. En las bolsas B y C los hongos y bacterias se ubicaron en el estrato superior (Figura 2).

En la bolsa $D$ la presencia de hongos y bacterias aumentó y generó la peor condición final (promedio de afección por hongos $55 \%$ y por bacterias $26 \%$ ) con d.e.s. entre condiciones $(p<0,05)$ para hongos y sin d.e.s. para bacterias, pero con una tendencia creciente. No se observaron d.e.s. entre puntos de muestreo. Asimismo, esta bolsa presentaba un alto $\mathrm{CH}$ de los granos $(13,2 \%$, condición final). Además, los granos alcanzaron en el estrato superior $32,5^{\circ} \mathrm{C}$ promedio en octubre.

En la bolsa $E$, que presentó 120 días de almacenaje extendido hasta el verano (05/01/2012), se pronunciaron los cambios de $\mathrm{CO}_{2}$ y la estratificación de la humedad. Los microorganismos se ubicaron también en el estrato superior al final del almacenamiento y el $\mathrm{CO}_{2}$ aumentó por encima de la tolerancia $(12,39 \%$ promedio) (Figura 3). Sin embargo, la actividad microbiana no fue crítica (afección promedio final $12 \%$ ). También se registraron aumentos de $\mathrm{T}^{\circ}$ en el verano (promedio $30,5^{\circ} \mathrm{C}$ en granos). En las bolsas restantes, el $\mathrm{CO}_{2}$ se mantuvo por debajo de la tolerancia durante el almacenamiento, con valores finales de: bolsa $A$ $1,6 \%$, bolsa B $4,3 \%$, bolsa C $1,3 \%$ y bolsa D $2,6 \%$.

Manchado de los granos. Relación con la actividad microbiológica.

El manchado de los granos aumentó en todas las bolsas (Figura 4). En la bolsa A se observa una relación significativa entre los granos manchados y los granos partidos $(r=0,95)$ situación que se observa especialmente en el estrato inferior a partir de los 110 días. También el contenido de ME mostró una relación significativa con los hongos $(r=0,63)$. La bolsa $B$ no mostró relación del manchado con otros parámetros.

La bolsa $\mathrm{C}$ presentó el mayor contenido final de granos manchados $(10,1 \%)$ con una relación significativa de los mismos con $\mathrm{CH}(\mathrm{r}=0,65)$ y con $\mathrm{CO}_{2}(\mathrm{r}=0,72)$. En la bolsa $\mathrm{D}$ los granos manchados presentaron una relación significativa con los hongos $(r=0,68)$ y con los granos partidos $(r=0,66)$. A su vez, la relación entre hongos y granos partidos también fue significativa $(r=0,83)$. La bolsa $E$ presentó el mayor porcentaje de granos manchados inicial y un elevado contenido de granos partidos. Las correlaciones de ambos parámetros con $\mathrm{CO}_{2}$ resultaron en: granos manchados vs. $\mathrm{CO}_{2}: \mathrm{r}=0,78$; granos partidos vs. $\mathrm{CO}_{2}: \mathrm{r}=0,58$.

\section{Interacción entre los parámetros: ME y granos} partidos.

La condición inicial de las bolsas reflejó una interacción estadísticamente significativa entre ME y granos partidos para el porcentaje de granos manchados $(p<0,05)$. Cuando se excluye del análisis la bolsa $D$ (granos con alto $\mathrm{CH}$ ) la interacción no resulta significativa. En ambos casos el efecto de los granos partidos sobre los manchados es significativo. 


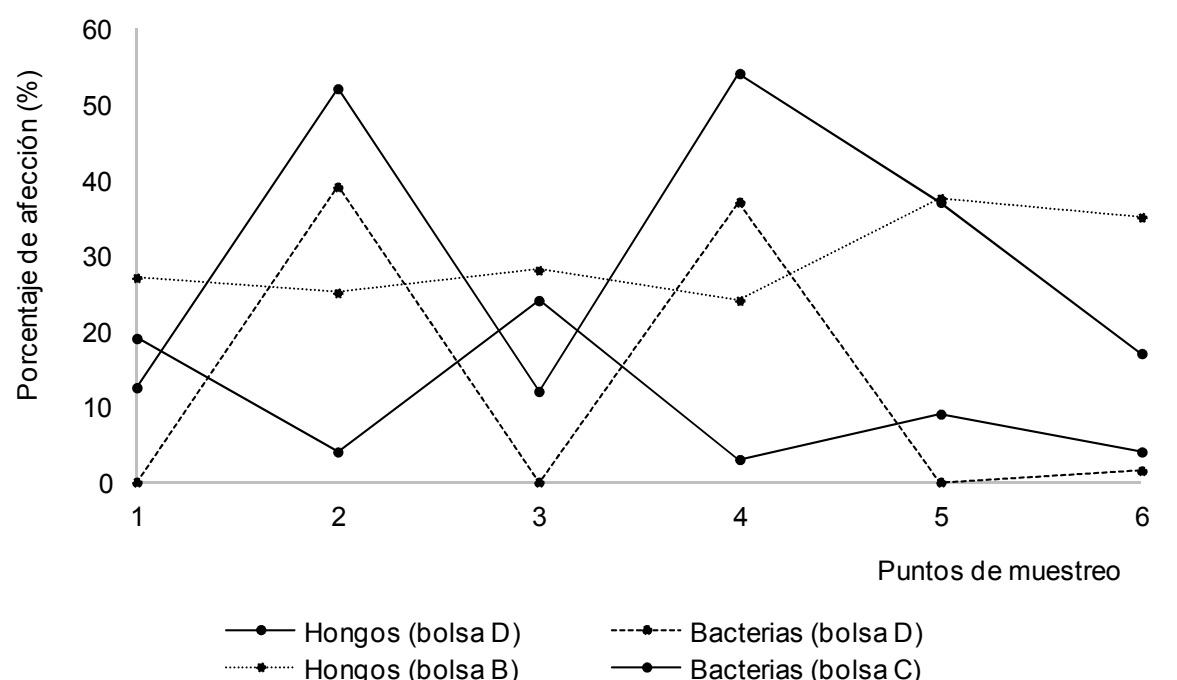

Figura 2. Distribución de los hongos y bacterias en los puntos de muestreo 2, 4 y 6 correspondientes a la base de la bolsa, $y$ en los puntos 1, 3 y 5 correspondientes al estrato superior.

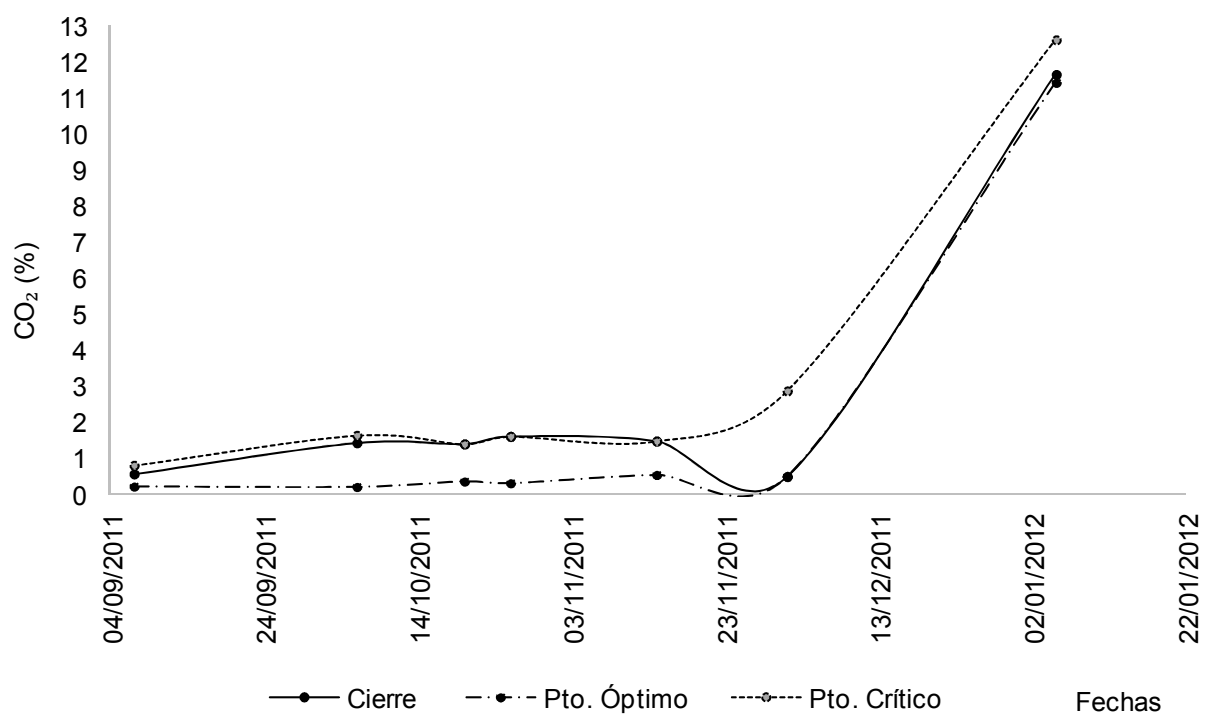

Figura 3. Registros de $\left[\mathrm{CO}_{2}\right](\%)$ en el período de almacenamiento de la bolsa $\mathrm{E}$.

La interacción entre granos partidos y $\mathrm{ME}$ en la condición final resultó estadísticamente significativa para la proporción de granos manchados al incluir y excluir del análisis la bolsa $\mathrm{D}$. El manchado se relaciona significativamente con la proporción de ME. A medida que avanza el tiempo de almacenamiento cobra importancia el efecto de ME en la interacción y produce la peor condición (Figura 5). El efecto de ME no está vinculado con el $\mathrm{CH}$ de los granos, mientras que el efecto de los granos partidos sí.

\section{Tiempo de almacenamiento seguro (TAS)}

A partir de los resultados obtenidos, es posible definir una aproximación del TAS en función del momento en que se produce el incremento de la actividad microbiológica y con ello de la concentración de $\mathrm{CO}_{2}$. Considerando las condiciones iniciales de almacenamiento para temperaturas menores a $30^{\circ} \mathrm{C} \mathrm{y}$ $\mathrm{ME}$ seco, y de acuerdo con las tolerancias comerciales, se proponen tres TAS: 1)- ME<tolerancia - $\mathrm{CH}$ del grano igual o menor a $10,5 \%$ - granos partidos<tolerancia: 158 días; 2)- ME>tolerancia - $\mathrm{CH}$ del grano igual o menor a $10,5 \%$ - granos partidos> ó <tolerancia: 120 días; 3)- ME>tolerancia - $\mathrm{CH}$ del grano mayor a 10,5\% - granos partidos>tolerancia: 95 - 100 días. Mayores temperaturas reducen el TAS. Asimismo, ME húmedo reduce el TAS, observándose que un $\mathrm{CH}$ de ME mayor a $60 \%$ disminuye el TAS a la mitad. 


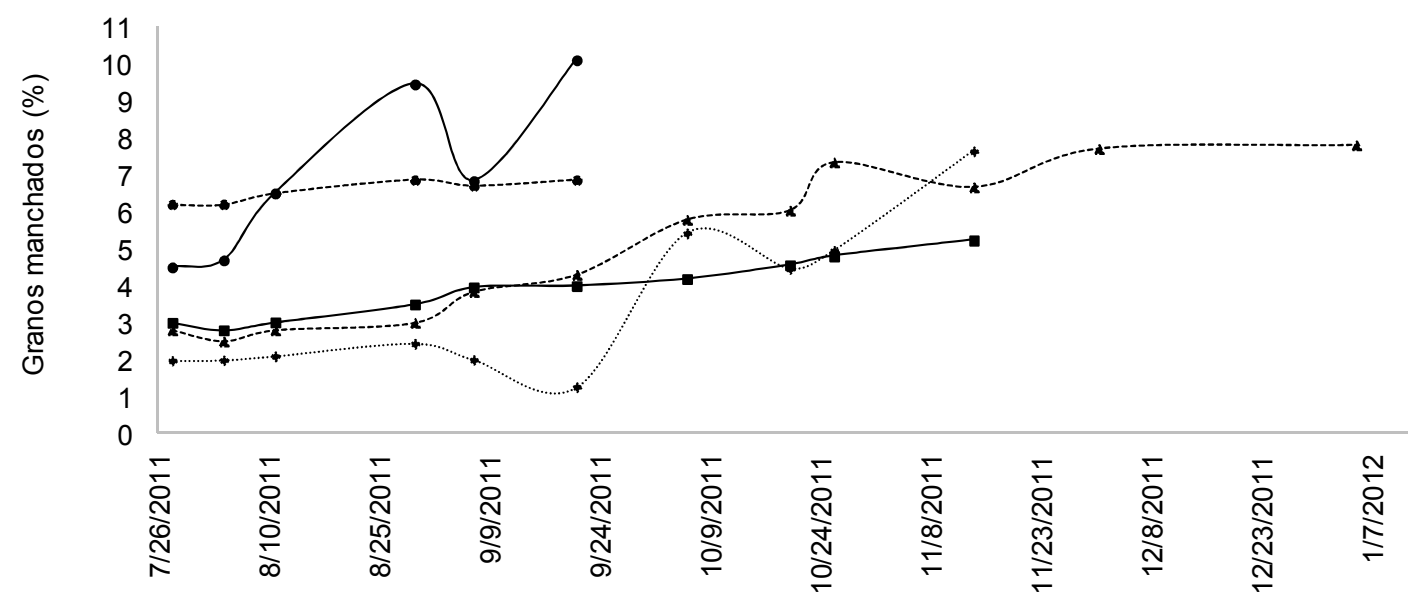

Fechas

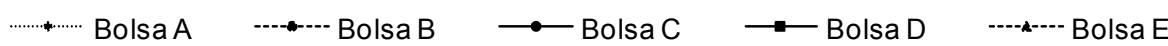

Figura 4. Evolución de los granos manchados (\%) en el período de almacenamiento de las bolsas evaluadas.

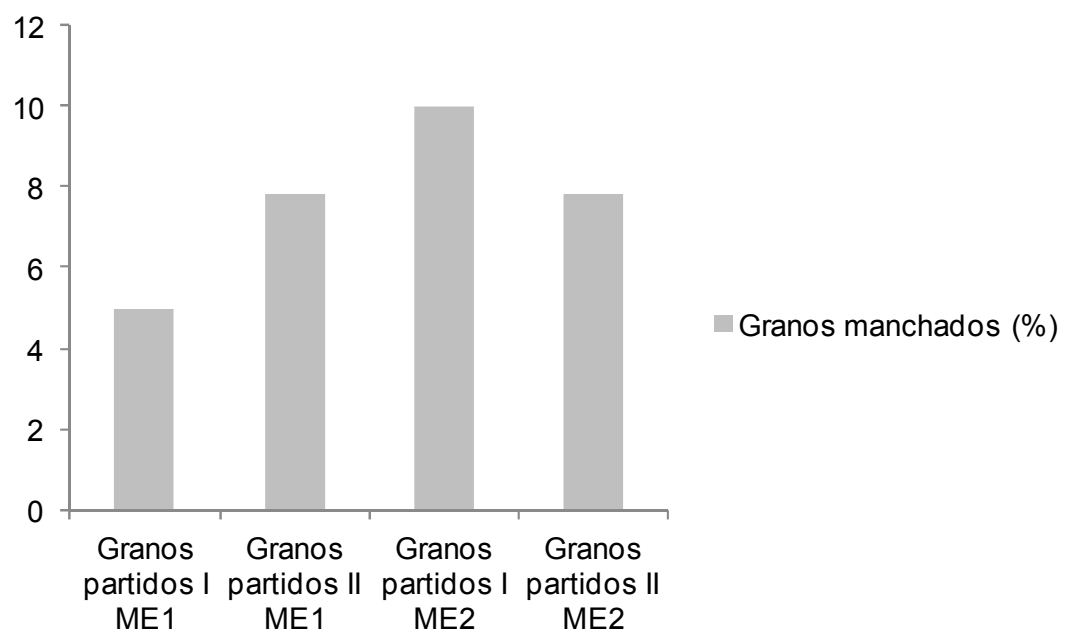

Figura 5. Interacción en la condición final de las bolsas entre ME y granos partidos para el manchado de los granos, donde $M E 1<2 \%$, ME2>2\%, granos partidos $K<4 \%$, granos partidos $I />4 \%$ contemplando la bolsa $D$ en el análisis.

\section{DISCUSIÓN}

La distribución de los hongos en la base de la bolsa $\mathrm{A}$ puede explicarse por el alto contenido de granos partidos especialmente concentrados en el estrato inferior, lo cual coincide con Cardoso et al., 2009. La ubicación de las bacterias siguió el mismo patrón y también puede vincularse a la estratificación de los granos partidos. La patogenicidad positiva de las bacterias desde el inicio del almacenamiento indica la posible infestación durante la cosecha, lo cual coincide con Weller \& Saettler, 1980. De igual manera ocurrió en las bolsas con altos contenidos de ME y granos partidos ( $D$ y $E$ ) donde los microorganismos también se ubicaron en la base de la bolsa coincidiendo con la estratificación del material fino. En las restantes (B y $C$ ) se ubicaron en el estrato superior, favorecidos por fenómenos de condensación resultante de movimientos de convección del aire intergranario. Ambos aspectos coinciden con los estudios de Cardoso et al., 2009.

En el período de almacenamiento la HRE generada en la bolsa $A$ produjo el control de microorganismos, en coincidencia con lo propuesto por Giner, 1994; Abadía \& Bartosik, 2013; De Simone, 1998 y Godoy, 2014a, quienes establecen aw<0,70 como parámetro de estabilidad microbiana.

Los aumentos de HR y $\mathrm{T}^{\circ}$ del aire intergranario en el estrato superior reflejan la influencia del ambiente externo y explican la estratificación de la humedad por condensación debida, como se expresó previamente, a 
movimientos de convección, lo cual coincide con Cardoso et al., 2009. Al igual que en los trabajos realizados por Bartosik et al., 2009 y Abalone et al., 2011 , la $\mathrm{T}^{\circ}$ del aire intergranario siguió el patrón de la $\mathrm{T}^{\circ}$ ambiente.

En las bolsas B, C y E también se produjo el control de microorganismos por la baja HRE generada, a excepción de la bolsa $\mathrm{D}$ donde el aumento de hongos y bacterias se debió a un HRE favorable para el desarrollo microbiano. Estas situaciones coinciden con las observadas por Giner, 1994; Abadía \& Bartosik, 2013; De Simone, 1998, y Godoy, 2014a.

La estratificación de la humedad y los cambios de $\mathrm{CO}_{2}$ se pronunciaron con el aumento del tiempo de almacenamiento y el cambio de estación a la temporada más cálida, tal como ocurrió en la bolsa $\mathrm{E}$, lo cual coincide con Bartosik et al., 2009 y Abalone et al., 2011. Sin embargo, en esta bolsa la actividad microbiana no fue crítica por lo que el incremento de $\mathrm{CO}_{2}$ puede relacionarse con un aumento en la tasa de respiración de los granos (enteros y partidos) y las ME. Esto es favorecido por aumentos de $\mathrm{T}^{\circ}$ en el verano y coincide con Bartosik et al., 2009; Godoy, 2014b.

El manchado de los granos puede considerarse como un indicador del desarrollo microbiano según los estudios de Godoy (2014a) y se evidencia claramente en la bolsa $D$ donde el mismo aumenta a medida que crece la afección con hongos. Asimismo, el incremento del manchado se explica por el contenido de granos partidos, de $\mathrm{ME}$ y el $\mathrm{CH}$ de los granos. Por otra parte, la concentración de dióxido de carbono, que es también un indicador de la actividad microbiológica se incrementa a medida que aumenta la proporción de granos manchados (coincide con Bartosik et al., 2009 y Godoy, 2014b). Todos estos aspectos se profundizan a partir de los 100 días, lo cual coincide con los estudios realizados por De Simone et al., 2009; De Simone \& Godoy (2009) y Godoy (2014a).

Estos incrementos de la proporción de granos manchados implican la disminución de la calidad comercial, lo cual se profundiza al almacenar granos húmedos, aspecto que coincide con los estudios de Bartosik et al. (2009), y Godoy (2014a-b).

La interacción significativa entre los contenidos de granos partidos y $\mathrm{ME}$, permite evidenciar la sinergia entre el efecto de cada uno de ellos sobre el manchado de los granos y explica cómo se complementan ocasionando la reducción de la calidad comercial.

\section{CONCLUSIONES}

Altos contenidos de material extraño y granos partidos propician el incremento de la actividad acuosa. Dicho incremento favorece la actividad microbiológica.

La ubicación de los microorganismos dentro del granel responde a dos situaciones:

Acompañan la distribución del material fino en la base de la bolsa.

Se emplazan en puntos del estrato superior de la bolsa que presentan altos contendidos de humedad, producto de la condensación del aire húmedo que se desplaza en el espacio intergranario por movimientos de convección. Existe migración de humedad desde el estrato inferior hacia el superior.
La actividad microbiana produce el manchado de los granos, a lo que se agrega la sinergia entre los efectos del material extraño y los granos partidos.

El efecto de la proporción de granos partidos está influenciado por la humedad de los granos, cuanto mayor es, mayor es el porcentaje de manchado.

El efecto negativo del material extraño crece en importancia a medida que aumenta el tiempo de almacenamiento.

Períodos prolongados y temperaturas elevadas favorecen la interacción entre material extraño y granos partidos, donde aumenta la tasa respiratoria del granel (incluido el grano). La acción integrada de ambos parámetros reduce la calidad comercial del poroto almacenado en silobolsa en condición de intemperie.

La proporción y condición de ME y granos partidos presentes en el granel, conjuntamente con el contenido de humedad inicial de los granos, deben considerarse para determinar el tiempo de almacenamiento seguro.

\section{Agradecimientos}

Al CPN Marcelo Camacho gerente de ALIMAR S.A. por la invalorable predisposición para lograr este trabajo. Al Sr. Hugo de ALIMAR S.A. por la colaboración permanente en el desarrollo del ensayo a campo. A las empresas fabricantes de silobolsa: IpesaSilo y PlastarGroup por el acompañamiento financiero para concretar el trabajo a través del convenio con INTA. Al personal de apoyo técnico de INTA Salta: Víctor Flores, Alejandro Chocobar y Gastón Brizuela por su trabajo continuo y responsable. Al personal de laboratorio de INTA Salta: Mario Chocobar y Oscar Sarapura por la dedicación minuciosa a cada muestra analizada.

\section{BIBLIOGRAFÍA}

Abadía B. \& R. Bartosik. 2013. Manejo Eficiente del Grano en la Poscosecha. En: Manual de buenas prácticas en poscosecha de granos. Editores: Abadía B. \& R. Bartosik. Ediciones INTA. I.S.B.N.: 978-987-679264-6. Buenos Aires, Argentina. pp: 22 - 30.

Abalone R., A. Gastón, R. Bartosik, L. Cardoso \& J. Rodríguez. 2011. Concentración de gas en la atmósfera intersticial de silobolsa de trigo. Parte II: Sensibilidad del modelo y efecto de las condiciones de almacenamiento del grano. Elsevier. Journal of Stored Products Research 47: 276 - 283.

ASAE. 1996. Norma ASAE S352 1996 - determinación de humedad de granos.

Bartosik R., J. C. Rodríguez, H. Malinarich \& L. Cardoso. 2009. Almacenaje de maíz, trigo, soja y girasol en bolsas plásticas herméticas. En: Almacenamiento de granos en bolsas plásticas. Ediciones INTA. I.S.S.N. 1667-9199. Córdoba, Argentina. pp: 2 - 14.

Cardoso L., R. Bartosik \& J. C. Rodríguez. 2009. Estudio de la evolución de la humedad de los granos individuales en bolsas plásticas de maíz y soja. En: Almacenamiento de granos en bolsas plásticas. Ediciones INTA I.S.S.N. 1667-9199. Córdoba, Argentina. pp: $23-33$.

De Simone M.E. 1998. Humedad de equilibrio en porotos (Phaseolus vulgaris L.) Disponible en: 
http://www.cosechaypostcosecha.org. Ultimo acceso: Julio 2017.

De Simone M.E. \& A.I. Godoy. 2006. Sistema de recolección directa. En: Poroto: Eficiencia de cosecha y postcosecha, PRECOP, manual técnico N4. Editor De Simone M. Ediciones INTA I.S.S.N. 1667 -9199. Córdoba, Argentina. pp: 23, 48, 50.

De Simone M. E. \& A. I. Godoy. 2009. Evaluación del efecto de media sombra en la calidad del poroto almacenado en bolsas plásticas con sistema de embolsado por gravedad. En: Almacenamiento de granos en bolsas plásticas Ediciones INTA I.S.S.N. 1667-9199. Córdoba, Argentina. pp: 169 - 180.

De Simone M.E., M.J. Fili \& A.I. Godoy. 2009. Almacenamiento de poroto (Phaseolus vulgaris L.) en bolsas plásticas con relación al contenido de humedad inicial, deterioro de los granos y el tiempo. En: Almacenamiento de granos en bolsas plásticas. Ediciones INTA I.S.S.N. 1667-9199. Córdoba, Argentina. pp: 162 - 168.

Giner S.A. 1994. Temas de post-cosecha de granos oleaginosos. Parte I. Aceites y Grasas, A\&G Técnica. pp: 71 - 83.

Godoy A.I. 2014a. Calidad de Poroto Blanco Alubia (Phaseolus vulgaris L.) almacenado en Bolsas Plásticas experimentales en relación a la presencia de Materias Extrañas en el granel. $1^{\circ}$ Congreso Internacional de Almacenamiento de Granos en Silobolsa. Libro de resúmenes. Editores Gastón A., R. Abalone \& R. Bartosik. Ediciones INTA I.S.B.N. 978-987-33-6146-3. Buenos Aires, Argentina. pp: 65 - 67.

Godoy A.I. 2014b. Silo bolsa de poroto. Concentración de dióxido de carbono en relación a las condiciones de almacenamiento. En: Almacenamiento de granos en silo bolsa. Resultados de investigación 2009 - 2013. Editores Cardoso L., R. Bartosik, D. de la Torre, B. Abadía \& M. Santa Juliana. Ediciones INTA I.S.B.N. 978-987-33-6221-7. Buenos Aires, Argentina. pp: 128 137.

Godoy A.I. \& M.E. De Simone. 2010. Almacenamiento de poroto en bolsas plásticas. Actualización técnica $\mathrm{N}^{\circ}$ 53. Ediciones INTA. Córdoba, Argentina. pp: 12.

Godoy A.I., M.E. De Simone \& F. Mónico. 2006. Manejo de la cosecha. En: Poroto: eficiencia de cosecha y postcosecha. PRECOP, manual técnico $\mathrm{N}^{\circ} 4$, PRECOP. Editor De Simone M. Ediciones INTA I.S.S.N. 1667-9199. Córdoba, Argentina. pp: 59 - 65.

Paoli H.P., J.N. Volante, L.M. Vale Laura Y. Noé, M.J. Mosciaro \& H.J. Helena. 2017. Cultivos extensivos de verano, Salta y Jujuy. En: Monitoreo de cultivos del Noroeste Argentino a partir de sensores remotos. ProReNOA. Campaña agrícola 2016-2017. Vol. 17, N 37. Ediciones INTA I.S.S.N. Edición Impresa N N $1851-$ 8109. I.S.S.N. Edición en Línea No 1851-8230. pp: 8.

SAGPyA. 1994. Norma de Poroto Blanco Seleccionado Oval y Alubia (Norma XVI - anexo A) Resolución 1075/94. Buenos Aires, Argentina.

Tubello D. \& A. Picollo. 2002. Producción, comercialización y mercados. En: El cultivo de poroto en la República Argentina. Editores De Simone M. \& V. Failde. Ediciones INTA I.S.B.N. 987-521-067-6. Salta, Argentina. pp: 255 - 265.

Weller D.M. \& A.W. Saettler. 1980. Colonization and distribution of Xanthomonas phaseoli and Xanthomonas phaseoli var. Fuscans in field-grown Navy Beans. Phytopathology. Ecology and Epidemiology Vol. 70, $\mathrm{N}^{\circ}$ 6. pp: $500-506$. 